\title{
O TEMPO LIVRE DOS TRABALHADORES DE UMA \\ INDÚSTRIA METALÚRGICA DA CIDADE DE CASTRO E SUA \\ RELAÇÃO COM A QUALIDADE DE VIDA NO TRABALHO \\ THE FREE TIME OF THE WORKERS OF A \\ METALLURGIC INDUSTRY OF THE CITY OF CASTRO \\ AND ITS RELATION TO THE QUALITY OF LIFE IN \\ WORK
}

Msdo. Marcelo Rugiski

Dr. Luiz Alberto Pilatti

PPGEP/CEFET-PR/Ponta Grossa

\begin{abstract}
Resumo
A presente pesquisa teve como objetivo discutir o tempo livre dos trabalhadores de uma indústria metalúrgica da Cidade de Castro, região centro sul do Paraná (Brasil). Trata-se de um levantamento que utilizou o questionário para a coleta de dados. O referencial teórico que norteou as discussões sobre o tempo livre baseou-se na teoria de Norbert Elias e Eric Dunning e para as discussões sobre a Qualidade de Vida no Trabalho foram utilizados as proposta de Limongi-França e o modelo teórico proposto por Walton. Constatou-se que no tempo livre dos referidos trabalhadores ocorre um predomínio das atividades rotineiras pouco prazerosas em relação às típicas atividades de lazer. Conclui-se que entre as ações que buscam a Qualidade de Vida no Trabalho, várias atividades têm estreita relação com o tempo livre dos trabalhadores.
\end{abstract}

Palavras-Chave: Qualidade de Vida; Qualidade de vida no trabalho; Tempo livre.

\section{Introdução}

No final do século XX, a responsabilidade social, o desenvolvimento sustentável e o aumento da expectativa de vida da população fizeram surgir novos paradigmas em relação à Qualidade de Vida (QV) e Qualidade de Vida no Trabalho (QVT).

A condição humana no trabalho torna-se uma das preocupações dos gestores e a qualidade de vida do trabalhador passa a ser tratada com maior zelo nas organizações. Limongi-França (2004, p. 42) afirma que há uma "íntima correlação entre melhoria da QV das Pessoas e Estilo da vida dentro e fora da organização" e que essa melhoria "causará impacto na excelência e na produtividade dos indivíduos em seu trabalho". Questões como o vínculo e a estrutura da vida pessoal, a família, atividades de lazer e 
esporte, hábitos de vida, expectativa de vida, cuidados com a saúde, alimentação, combate à vida sedentária, grupos de afinidades e apoio passam a ser desencadeadores de QVT, os quais se encontram presentes no tempo livre das pessoas.

Baseado nisso, a presente pesquisa teve como objetivo discutir o tempo livre dos trabalhadores de uma indústria metalúrgica da Cidade de Castro, na região centro sul do Paraná, bem como, a sua relação com a QVT. O referencial teórico que norteou as discussões sobre o tempo livre baseou-se na teoria de Norbert Elias e Eric Dunning e para as discussões sobre a QV no Trabalho foram utilizados as proposta de LimongiFrança e o modelo teórico proposto por Walton.

\section{QVT}

O tema QVT, tal qual a QV, é tratado de sob inúmeros aspectos. As definições de QVT variam desde os cuidados estabelecidos pela legislação médica e a segurança do trabalho, até atividades de cunho voluntário que envolvem empregados e empregadores em áreas como: lazer, motivação, entre outras. A maioria discute as condições do trabalho, do bem-estar do indivíduo e de grupos. (LIMONGI-FRANÇA, 2004).

Para Limongi-França (2004, p. 24),

a base da discussão sobre o conceito de QV encerra escolhas de bem-estar e percepção do que pode ser feito para atender às expectativas criadas tanto por gestores como por usuários de ações de QV na empresa.

Por considerar a pluralidade de indicações e a diversidade de formas de discussão, a autora propõe agrupar as dimensões sobre o tema QVT em Escolas do Pensamento. As Escolas do Pensamento propostas são: Socioeconômica, Organizacional e Condição Humana no Trabalho (LIMONGI - FRANÇA, 2004).

Com relação à Escola Socioeconômica vale destacar a análise das relações de trabalho no mundo globalizado e seus paradoxos. A cidadania, responsabilidade social, igualdade, preservação do meio ambiente e o desenvolvimento sustentável passam a fazer parte do contexto da empresa e em sua relação com o trabalho.

A Escola Organizacional é composta por um extenso conjunto de contribuições sob uma perspectiva organizacional referente à competência, estratégia, cultura e 
talento. Deste conjunto podem-se destacar as seguintes características: expansão de processos de qualidade e produtividade para o de qualidade pessoal; política de gestão de pessoas - valorização e capacitação; marketing - imagem corporativa; tempo livre desenvolvimento cultural, hábitos de lazer e esporte; risco e desafio como fatores de motivação e comprometimento.

Por último, a Escola Condição Humana no Trabalho mostra que a pessoa é um ente biopsicossocial, que tem potencialidades biológicas, psicológicas e sociais e que estes fatores "são fundamentais para a explicação da saúde e da doença da sociedade moderna" (LIMONGI-FRANÇA. 2004, p. 28).

A Visão biopsicossocial está assim fundamentada:

$>$ dimensão biológica: diz respeito às características físicas que o indivíduo herda ou adquire ao nascer e também durante toda vida. Inclui metabolismo, resistência e vulnerabilidade de seus órgãos e sistemas;

$>$ dimensão psicológica: esta dimensão refere-se aos processos afetivos, emocionais e de raciocínio, conscientes ou inconscientes, que formam a personalidade de cada pessoa e seu modo de perceber e de posicionar-se diante das demais pessoas e das circunstâncias que vivencia;

$>$ dimensão social: revela os valores socioeconômicos, a cultura e as crenças, o papel da família e as outras formas de organizações sociais, no trabalho e fora dele, os sistemas de representação e a organização da comunidade a que cada pessoa pertence e da qual participa. O meio ambiente e a localização geográfica também formam a dimensão social.

Lemongi-França (2004) considera que a idéia de criar as Escolas de Pensamento em QVT, as quais integraram e localizaram as demandas de QV dentro das empresas, pode vir a ser um avanço importante em direção à consolidação de uma nova competência gerencial identificada em QVT. As dimensões socioeconômicas, organizacionais e de condições humanas no trabalho poderão possibilitar a definição de critérios, procedimentos metodológicos e novos esforços e práticas organizacionais que 
viabilizem a QVT nas empresas.

Outra leitura sobre QVT a ser destacada, parte de Walton que foi o primeiro autor norte- americano a fundamentar, um conjunto de critérios "sob a óptica organizacional, iniciando importante linha de pesquisa de satisfação em QV no trabalho" (LIMONGIFRANÇA, 2004, p. 32).

Pilatti e Bejarano (2005, p. 97) consideram Walton,

como uma espécie de referência quase obrigatória nos estudos da QVT' e tecem o seguinte comentário:

Para o autor, a idéia de QVT é calcada em humanização do trabalho e responsabilidade social da empresa, envolvendo o entendimento de necessidades e aspirações do indivíduo, através da reestruturação do desenho de cargos e novas formas de organizar o trabalho, aliado a uma formação de equipes de trabalho com um maior poder de autonomia e uma melhoria do meio organizacional.

O modelo teórico proposto por Walton possibilita abalizar o nível de QVT a partir de oito categorias conceituais, que incluem: compensação justa e adequada, condições de trabalho seguras e saudáveis, oportunidade imediatas para desenvolver e usar capacidades humanas, oportunidades futuras para o crescimento contínuo e a garantia de emprego, integração social e constitucionalismo na organização, trabalho e espaço total na vida do indivíduo e relevância social do trabalho.

\section{Atividades do Tempo Livre}

No dois primeiros capítulos da obra "A busca da excitação", de Elias e Dunning (1992), é possível compreender as relações e as diferenças das várias atividades de tempo livre. Para melhor entender estas diferenças, propõe-se uma distinção maior e mais aprofundada e também uma definição mais nítida das relações do tempo livre.

Para os autores

tempo livre, de acordo com os atuais usos lingüisticos, é todo tempo liberto das ocupações de trabalho", e ainda mostram que é possível distinguir "cinco esferas diferentes no tempo livre das pessoas, as quais se confundem e se sobrepõem de várias maneiras, mas que representam categorias diferentes de afetividades, que até certo ponto, levantam problemas diferentes (ELIAS; DUNNING, 1992, p. 107-108). 
Para isso, em uma classificação preliminar, as atividades do tempo livre são divididas em cinco esferas representadas por:

> trabalho privado e administração familiar: a essa categoria pertencem às atividades relacionadas aos cuidados com a família e também as atitudes tomadas em relação à provisão da casa;

$>$ repouso: atividades como dormir, tricotar, futilidades da casa e o não fazer nada em particular;

$>$ provimento das necessidades fisiológicas: comer, beber, dormir, bem como, defecar e fazer amor;

> sociabilidade: atividades como passear em um clube, um bar, um restaurante, "jogar conversa fora" com os vizinhos, ou mesmo estar com outras pessoas sem fazer nada demais, como um fim em si mesmo;

$>$ categoria das atividades miméticas ou jogo: as atividades desse tipo são atividades de tempo livre que possuem caráter de lazer, quer se tome parte nelas como ator ou como espectador. Essas atividades estão diretamente associadas à destruição da rotina, que é uma característica da excitação mimética.

Para entender e compreender as diferenças entre as variadas atividades de tempo livre, entre as quais se insere o lazer, Elias e Dunning(1992, p. 145), utilizam o conceito "espectro do tempo livre" em que identificam as demais atividades, além do trabalho, que são executadas de forma rotineira.

As atividades transcorridas no tempo livre, isto é, no tempo liberado do trabalho profissional, são muito variadas. Podemos citar, as atividades sociais, de convívio com a família e até mesmo cuidados pessoais. A partir disto, tem-se a necessidade de uma melhor conceituação de tempo livre. Para Elias e Dunning, essas atividades foram classificadas conforme o que eles chamam de "grau de rotina" e foram separadas em três grupos distintos:

$>$ atividades rotineiras: cuidados com higiene e alimentação, tarefas domésticas, atenção a familiares etc.; 
atividades de formação e autodesenvolvimento: trabalho social voluntário, estudo não escolar, hobbies, atividades religiosas, participação em associações, atualização de conhecimentos etc., e

$>$ atividades de lazer: encontros sociais formais ou informais, jogos e atividades miméticas, como participante ou como espectador; miscelânea de atividades esporádicas prazerosas e multifuncionais, como: viagens, jantares em restaurantes, caminhadas, etc.

O termo mimético não é utilizado em seu sentido literário "imitativo". Elias e Dunning (1992, p. 124-125) comentam que "já na Antigüidade era usado num sentido mais amplo e figurado. Referia-se a todas as espécies de formas artísticas na sua relação com a 'realidade', quer possuíssem um caráter de representação ou não". Com efeito, na teoria elisiana, o termo deve ser compreendido como o sentido de uma "relação entre os sentimentos miméticos e as situações sérias específicas da vida" (ELIAS, DUNNING, 1992, p. 125-126). Nas situações sérias da vida, as pessoas podem perder o controle e assim tornarem-se um perigo para si e para outros. A excitação mimética, na perspectiva social e individual, é desprovida de perigo, proporcionando às pessoas experimentarem a explosão de fortes emoções em público, um tipo de excitação que não coloca em risco a ordem da vida social como ocorre nas situações sérias da vida.

\section{Metodologia}

O presente trabalho, do ponto de vista de sua natureza, classifica-se como uma pesquisa aplicada. Para Salomon (1999 p. 158), pesquisas aplicadas "são as que se destinam a aplicar leis, teorias e modelos, na solução de problemas que exigem ação e/ou diagnóstico de uma realidade". Baseado nesta afirmação pode-se argumentar que o estudo conforma-se como aplicado, pois busca conhecer a realidade das atividades realizadas no tempo livre dos trabalhadores de uma indústria metalúrgica.

Este trabalho foi abordado na perspectiva prioritariamente qualitativa e com relação aos objetivos da pesquisa, pode ser classificada de descritiva. A respeito da pesquisa descritiva, Gil (1999, p. 44), diz que este tipo de pesquisa "tem como objetivo primordial a descrição de determinadas características de determinada população ou 
fenômeno" e salienta que a utilização de técnicas padronizadas para a coleta de dados é uma de suas características mais marcantes.

A pesquisa foi desenvolvida na forma de "surveys" e para a coleta de dados foi utilizado um formulário composto por dois procedimentos. Um instrumento baseado na Escala de Likert e um questionário composto por perguntas abertas e fechadas. Este formulário foi validado e aplicado na própria empresa durante o horário de trabalho.

Os elementos que compunham o universo eram trabalhadores de uma indústria metalúrgica da cidade de Castro, localizada no Centro sul do Estado do Paraná. A amostra foi composta através do procedimento de amostragem aleatória simples, com a utilização de tábuas de números aleatórios.

Tendo uma população finita de 56 funcionários, a amostra totalizou 26 pessoas, com um desvio padrão de 2,31, o que é considerável em uma amostra de $55 \%$ da população e que mensura com um erro de 0,41 .

A amostra foi composta em sua grande maioria de pessoas do sexo masculino, com média de idade de 27 anos, casados, residentes na zona urbana e a média salarial gira em torno de quatro salários mínimos.

Para descrever os dados utilizou-se a estatística descritiva. A análise das informações foi feita com o uso do método de análise do conteúdo. As respostas dos entrevistados foram tabuladas, analisadas e confrontadas com o marco teórico da pesquisa, tendo em vista o objetivo proposto.

\section{Apresentação dos Resultados}

Para conhecer a realidade em relação às atividades de tempo livre, foram formuladas questões baseadas na escala de Likert, onde era solicitado que os entrevistados indicassem a freqüência em relação a cada um dos enunciados, segundo a graduação: Sempre (5), com freqüência (4), às vezes (3), raramente (2), nunca (1). Os resultados serão apresentados através de percentuais e as médias foram conseguidas através do cálculo da média ponderada. 
Buscando conhecer quais atividades eram mais freqüentes no tempo livre destes trabalhadores, a próxima questão foi dividida em cinco grupos correspondentes às esfera do tempo livre propostas por Elias e Dunning.

No primeiro grupo encontravam-se as atividades relacionadas com o trabalho privado e a administração familiar. Este grupo obteve uma média de 3,9, o que indica que com freqüência estas tarefas são encontradas no tempo livre do grupo pesquisado. Em termos percentuais, $48 \%$ dos entrevistados responderam sempre, $23 \%$ optaram por com freqüência, apenas $6 \%$ escolheram às vezes e $19 \%$ responderam raramente e nunca apenas $3 \%$.

$\mathrm{O}$ segundo grupo era composto por atividades relacionadas às consideradas de repouso. Para este grupo a média ficou em 3,4, o que mostra que estas atividades não são realizadas com tanta freqüência, mas apenas às vezes. A divisão desta questão ficou em: $23 \%$ sempre, $29 \%$ com freqüência, $23 \%$ às vezes, $23 \%$ raramente e por último, nunca $\operatorname{com} 2 \%$.

$\mathrm{O}$ terceiro grupo relacionava-se às necessidades biológicas. A média relacionada a estas ações alcançou o valor de 4,4, o que indica que as mesmas sempre fazem parte do tempo livre dos entrevistados. A soma de sempre e com freqüência ficou em $87 \%$, contra apenas $10 \%$ às vezes e $3 \%$ raramente.

Compunham o quarto grupo as atividades sociais. Com uma média de 3,6, estas atividades aparecem com freqüência no tempo livre. Neste grupo a divisão ficou em $23 \%$ sempre, $32 \%$ com freqüência, $32 \%$ às vezes e raramente e nunca ambos com $6 \%$.

Por último, foram levantadas as opiniões sobre atividades miméticas ou jogo. A média recebida por estas atividades foi 3,3 demonstrando que apenas às vezes os trabalhadores realizam atividades referentes a este grupo. Com relação a estas atividades apenas $2 \%$ optaram pela alternativa sempre, $26 \%$ escolheu com freqüência, $39 \%$ ficou com às vezes, $23 \%$ raramente e $6 \%$ nunca.

\section{Análise e Discussão}

Neste momento, para que se possa analisar as atividades do tempo livre e sua relação com a QVT, retoma-se alguns conceitos mostrados anteriormente. Tempo livre, 
de acordo com os atuais usos lingüísticos, é todo tempo liberto das ocupações de trabalho. Já ficou evidenciado que, para Elias e Dunning, as atividades do tempo livre estão distribuídas em cinco esferas e para que se possa realizar a discussão, estas categorias não foram dispostas na seqüência apresentada anteriormente.

Compõem a primeira categoria o trabalho privado e administração familiar; a este grupo pertencem às atividades relacionadas a atitudes tomadas em relação aos cuidados com a família e também com a casa. Destaca-se nas respostas, que este grupo de atividades aparece com freqüência no tempo livre dos entrevistados.

A quarta categoria relaciona-se as atividades de sociabilidade: Estas atividades podem variar em uma escala de sociabilidade que vai do informal ao formal. Os entrevistados indicaram que estas atividades apenas às vezes estão presentes em seu tempo livre.

Dentro do quadro teórico da QVT apresentado, pode-se dizer que estes dois grupos encontram-se diretamente relacionados com a sétima categoria conceitual de Walton, denominada de "Trabalho e espaço total de vida", sendo este um dos fatores da satisfação em QVT. Dentro desta categoria destacam-se dois elementos: 1) a importância do papel balanceado no trabalho: equilíbrio entre jornadas de trabalho, as exigências da carreira e o convívio familiar; 2) estabilidade de horários: horários previsíveis para o trabalho, lazer família, atividades sociais e a participação na comunidade (PILATTI; BEJARANO, 2005; RECHZIEGEL, 2001; RODRIGUES, 2002).

Estas duas categorias têm ligação com a "Visão Biopsicossocial" de LimongiFrança, e as atividades encontram-se na "esfera Social” (PILATTI; BEJARANO, 2005), na qual estão agrupados os elementos como: melhoria das condições de vida pessoal e familiar e a interação entre o indivíduo e o meio ambiente.

$\mathrm{Na}$ segunda categoria encontram-se as atividades relacionadas ao repouso: atividades como dormir, artesanato, futilidades da casa e o não fazer nada em particular. Para este grupo a média ficou em 3,4, o que mostra que estas atividades não são realizadas com tanta freqüência mas apenas, às vezes.

A terceira categoria é formada pelas atividades ligadas ao provimento das necessidades biológicas: necessidades como comer, beber, dormir, bem como, defecar e 
fazer amor. As atividades relacionadas com este grupo estão sempre presentes no tempo livre dos trabalhadores. Este grupo obteve a média de 4,4, indicando que estas atividades sempre fazem parte do tempo livre dos trabalhadores.

Estas duas categorias também estão relacionadas com a "Visão Biopsicossocial", estas atividades referem-se à "esfera biológica" (PILATTI; BEJARANO, 2005), onde estão agrupados elementos como; sono, alimentação, atividade física; intervenções clínicas; medicação e vitaminas; técnicas de distensão e repouso, e adequação do estilo de vida às necessidades individuais.

Esta última categoria é constituída pelas atividades miméticas ou jogos. As atividades deste tipo são atividades de tempo livre que possuem caráter de lazer, quer se tome parte nelas como ator ou como espectador. Estas atividades estão diretamente associadas à destruição da rotina, característica essa, da excitação mimética. A média recebida por estas atividades foi 3,3 o que demonstrou que as atividades deste grupo apenas às vezes fazem parte do tempo livre destes trabalhadores.

As atividades deste grupo fazem parte do conjunto de contribuições da Escola Organizacional, a qual faz referência ao tempo livre tendo como elementos o desenvolvimento cultural e a criação de hábitos de lazer e esporte. Ações de incentivo neste sentido podem ser vistas no resultado de uma pesquisa na qual 60 executivos de um curso de MBA - Recursos Humanos respondiam questões sobre QVT. Destaca-se para este trabalho as respostas da questão onde "os alunos deveriam informar quais atividades eram desenvolvidas nas empresas sob a sigla QVT" (LIMONGI-FRANÇA 2004, p. 136). As ações descritas tinham relação às dimensões Psicológicas e Organizacionais. Na Dimensão Psicológica, encontravam-se ações referentes ao lazer externo: caminhadas ecológicas, passeio ciclístico; e incentivo à participação em atividades sociais por meio da venda de ingressos para teatro, shows, entre outros eventos; e na Dimensão Organizacional o lazer interno: espaço de lazer com tv, jornais, revistas; sarau das 5; grupo de coral, teatro; biblioteca; jogos de futebol interno.

Faz-se necessário ressaltar neste momento, que normalmente o termo "tempo livre" é tratado como sinônimo de lazer. Como exemplo disto, destaca-se o resultado da $20^{\circ}$ reunião, realizada pela Rede de Estudos em Gestão da QV no Trabalho (REGQVT), onde o tempo livre foi um dos temas discutidos. Os principais termos utilizados 
para descrever o tempo livre foram: fazer o que quiser (64\%), prazer $(20 \%)$, nada (7\%), lazer (3\%), criatividade (3\%), e ócio (3\%) (LIMONGI-FRANÇA, 2004).

Para Elias e Dunning, como já foi mostrado, só parte do tempo livre pode ser voltada ao lazer, como é mostrado através dos três grupos do "grau de rotina": atividades rotineiras, atividades de formação e autodesenvolvimento e atividades de lazer.

As atividades rotineiras são consideradas por Elias e Dunning como muito rotineiras e pouco prazerosas. Estas tarefas dificilmente podem ser chamadas de lazer.

Atividades de formação e auto desenvolvimento podem até ser menos rotineiras que as primeiras e até gratificantes, "porém exigem disciplina e, em grande medida, a manutenção da conduta civilizada que reprime manifestações espontâneas" o que às vezes se distinguem das atividades da classe miméticas, que serão descritas logo mais, tais como o esporte (PRONI, 2001, p. 123).

Por fim, encontram-se as típicas atividades de lazer, estas são associadas à destruição da rotina e são caracterizadas pelo "descontrole controlado" diante das restrições dos impulsos e das emoções. Estas atividades proporcionam ao indivíduo oportunidades para vivenciar experiências que normalmente são alheias a setores altamente rotineiros da vida social e que normalmente precisam de um ambiente próprio ou situações especiais para que sejam aprovadas socialmente.

\section{Considerações Finais}

Considerando o resultado do levantamento realizado com os trabalhadores, podese inferir que no tempo livre dos atores pesquisados existe o predomínio das atividades rotineiras, as quais são encontradas nos dois primeiros grupos da classificação dos "graus de rotina" de Elias e Dunning. As atividades típicas de lazer que compõem o terceiro grupo foram as que tiveram o menor percentual com relação à freqüência no tempo livre do grupo pesquisado.

Esta tipologia apresentada, serve para demonstrar que a utilização do termo tempo livre, como sinônimo de lazer, não é verdadeira, mostrando de forma muito nítida, que 
uma parcela considerável do tempo livre dos indivíduos pesquisados não pode ser considerada como lazer.

Baseado nas Escolas de Pensamento em QV no Trabalho de Limonge-França e nas categorias de Walton, conclui-se que entre as ações que buscam a QVT, várias atitudes estão estreitamente relacionadas com o tempo livre dos trabalhadores.

Em termos práticos pode-se dizer que os gestores que tenham a preocupação com a QVT entre os objetivos organizacionais, devem atentar para a QV de seus funcionários não só quando estes estão na labuta, mas também, com a vida destes, além dos portões da fábrica.

\begin{abstract}
The objective of this research is to discuss workers' free time. The study took place at a metallurgical company in the city of Castro, Paraná, southern Brazil and it was undertaken as a survey, using a questionnaire to gather data. The theoretical framework about free time was based on the work of Norbert Elias and Eric Dunning, and the discussions about Quality of Work Life were based on the work of Limongi-França and the theoretical model proposed by Walton. It was observed that during these workers' free time, routine actives that are usually considered low-pleasure in relation to typical leisure activities were predominant. The conclusion was that, among activities aimed at QWL, several activities are closely related to workers' free time.
\end{abstract}

Key-Words: Life quality; Quality of work life; Free time.

\title{
Referências Bibliográficas
}

ELIAS, N.; DUNNING, E. A busca da excitação. Lisboa: Difel, 1992.

GIL, A. C. Métodos e técnicas de pesquisa social. 5. ed. São Paulo: Atlas, 1999.

LIMONGI-FRANÇA, A. C. $Q V$ no trabalho: conceitos e práticas na sociedade pósindustrial. São Paulo: Atlas, 2004.

PILATTI, L. A.; BEJARANO, V. C. QV no trabalho: leituras e possibilidades no entorno. In: GONÇALVES, A.; GUTIERREZ, G. L.; VILARTA, R. (Org.). Gestão da QV na empresa. Campinas: IPES Editorial, 2005.

PRONI, M. W. A teoria do lazer de Elias e Dunning. In: SIMPÓSIO INTERNACIONAL PROCESSO CIVILIZADOR, 6., 2001, Assis. Coletânea... Assis: Lasergráfica, 2001. 
RECHZIEGEL, W. Satisfação com a QV no trabalho no nível operacional: um estudo de caso em uma grande empresa do setor de autopeças. In: ENCONTRO NACIONAL DE ENGENHARIA DE PRODUÇÃO, 21., 2001, Salvador. Anais... Salvador: FTC, 2001.

RODRIGUES, C. M. C. QV no trabalho na Coinbra S/A: um levantamento do nível de satisfação dos funcionários. In: ENCONTRO NACIONAL DE ENGENHARIA DE PRODUÇÃO. 22., 2002, Curitiba. Anais... Curitiba: PUCPR, 2002.

SALOMON, D. V. Como fazer monografia. 9. ed. São Paulo: Martins Fontes, 1999. 